Article

\title{
Setting Headways on a Bus Route under Uncertain Conditions
}

\author{
Weiya Chen * $\mathbb{D}$, Xin Liu, Dingfang Chen and Xin Pan
}

School of Traffic and Transportation Engineering, Central South University, Changsha 410075, China; liuxin_1116@foxmail.com (X.L.); chendingfang0901@foxmail.com (D.C.); panxin@csu.edu.cn (X.P.)

* Correspondence: wychen@csu.edu.cn

Received: 26 March 2019; Accepted: 13 May 2019; Published: 17 May 2019

\begin{abstract}
Urban public transport is a sustainable transportation strategy. Promoting public transport is an important means of urban transport sustainable development. Reasonable operation scheduling can increase the attractiveness of public transit systems and be conducive to the sustainability of transportation systems. Setting headways on a bus route is the key work of bus scheduling. For the refined management requirements of bus scheduling, this paper comprehensively considers the influence of three uncertainties on the bus route headway: passenger demand elasticity, which is an elasticity with respect to the supply of service, the randomness of the bus travel time between bus stops, and the abandoned passengers flow. A bus route headway allocation model is established. Considering the attractiveness of bus traveling and the interests of passengers, the objective functions are the maximum number of passengers waiting for the bus at each stop and the minimum number of passengers who fail to board. An enumeration combining a recursive algorithm under Monte Carlo random simulation conditions is designed to solve the problem. A comparison of the optimal bus departure interval (headway of the origin stop) under different conditions is studied using a numerical case. Under the same conditions, the results show that the model proposed in this paper can reduce the passengers waiting time and attract more passengers traveling by bus and it also meets the goal of sustainable public transport well. These findings are significant references for optimizing bus operations considering these uncertain factors.
\end{abstract}

Keywords: urban traffic; bus frequency allocation; passenger demand elasticity; dynamic headway; abandoned passengers flow; stochastic simulation

\section{Introduction}

\subsection{Backgrounds}

With the growing volumes of passenger and freight flows in recent years, many scholars have put forward a range of research viewpoints on how different transportation modes can better meet needs, and improve transportation efficiency and service levels, such as airline transportation [1], liner shipping [2], passengers railway transportation [3] and also BRT (Bus Rapid Transit) transport system [4]. The same for bus transportation systems, as it is necessary to develop novel engineering concepts to improve performance. The urban bus system is of considerable significance for the sustainable development of transport systems and also the robust operation of society [5]. A proper bus operational system is critical in the view of increasing passenger demand. The allocation of bus headway is the basic task in realizing scientific bus dispatching and a reasonable bus headway can increase the attractiveness of bus traveling, as well as be conducive to the implementation of sustainable development strategy of transit priority. But the bus frequency is affected by many factors, 
such as passenger demand, road traffic conditions, bus service level regulation, bus enterprise resource allocation and management level, etc. A review of the literature on bus headway allocation is as follows.

\subsection{Literature Review}

The headway allocation problem is complex, so early research usually took the fixed passenger demand or fixed bus travel time as the assumptions, and proposed many models with different objectives, such as passenger waiting time [6,7], passenger cost [8-10], bus system fulfilment [11,12], the profit of both passengers and the bus enterprise [13], etc. However, it is well-known that bus travel time between bus stops is not fixed and it will fluctuate according to various factors such as traffic jams and accidents, etc. Passenger demand will also change with many factors.

With the development of operational scheduling intelligence and the refinement of operational management, researchers have gradually explored the impact of uncertain passenger demand and random road traffic conditions on the bus headway and the frequency allocation problem under uncertain conditions. Wang Chao et al. [14] introduced a congestion coefficient to describe the impact of road congestion on the bus headway and constructed an optimization model under the uncertainty of the bus headways. Chen Weiya et al. [15] considered the randomness of the bus traveling time between stops, which influences the vehicle load inhomogeneity, and proposed a frequency optimization model under random bus traveling time conditions. Li [16] considered the randomness of factors such as passenger arrivals, bus travel time, and boarding/alighting when optimizing the bus headways. Luigi dell'Olio et al. [17] put forward a bi-level which allows buses of different sizes to be assigned to public transport routes, thereby optimizing the headways on each route in accordance with observed levels of demand. Sharma et al. [18] built a single bus line headway optimization model considering the case of balking and reneging. Ceder [19] proposed that passengers leaving the stop were among the passengers who failed to board because of the waiting time (or headway) and established a frequency allocation model. Delle Site and Filippi [20] developed an optimization model, which optimized bus corridors with short-turn strategies and variable vehicle size. Yulin et al. [21] analyzed the possibility that passengers who failed to board due to vehicle overcrowding would have the choice of waiting for a subsequent vehicle or leaving the stop to seek another mode of transportation. Herbon [22] considered the passenger demand elasticity of the stop, and used the generalized newsvendor model to establish the bus frequency and vehicle capacity optimization model. Verbas [23] analyzed the effect of the elasticity of passenger flow on the bus frequency, and proposed a method for calculating the space-time elasticity of passenger flow, also introducing space-time elasticity into the frequency allocation model. Tian [24] extended Verbas's model and established a frequency optimization model based on stop demand elasticity, the objective functions of which are the minimum of a bus single trip time and the maximum profit of bus operators. Frei et al. [25] estimated and discussed stop-level transit elasticities with respect to service frequency, while some scholars have also assumed that passenger travel demand is related to the distance between stops [26]. In order to estimate ridership elasticity, Verbas used three main methodologies with respect to headway, compared in the context of a transit network frequency setting framework [27]. Hadas $Y$ et al. [28] presented a new approach of frequency setting by enabling the use of stochastic properties of the collected data and its associated costs within a supply chain optimization model.

The collected studies above optimized the bus headway from different perspectives, or taken the fixed bus travel time and passenger demand as assumptions, or considered the uncertainty of bus travel time, or considered the uncertainty of passenger flow (passenger demand elasticity or some passengers leave the stop because of failing to board or the long waiting time). But there is essentially no study that considers all of these uncertainties comprehensively. Thus, this paper proposes a bus headway optimization model that takes the three main uncertainties into account: the passenger flow elasticity, the randomness of the bus travel time between bus stops and the abandoned passengers flow. Considering the attractiveness of bus traveling and the interests of passengers, the objective functions are the maximum number of passengers waiting for the bus vehicle at each stop and the 
minimum number of passengers who fail to board. By considering the three stated uncertainty factors comprehensively, the model is more robust and is more in line with the actual production and operation of most bus routes.

\section{Problem Description and Modeling}

\subsection{Variables and Symbol Descriptions}

The variables and symbols used in this paper are shown in Table 1.

Table 1. Variables and symbols descriptions.

\begin{tabular}{|c|c|}
\hline$H$ & Headway of the Origin Stop (Min) \\
\hline$i$ & number of buses, $\mathrm{i}=1,2 \ldots \mathrm{N}$ \\
\hline$k$ & stop serial number, where $\mathrm{k}=1,2 \ldots \mathrm{K}$ \\
\hline C & maximum passenger capacity of the vehicle (seats) \\
\hline$\alpha / \beta$ & average passenger alighting and boarding time ( $\mathrm{min})$ \\
\hline$\lambda_{\mathrm{k}}$ & average passenger arrival rate at stop $\mathrm{k}(\mathrm{p} / \mathrm{min})$ \\
\hline$\mu_{\mathrm{ik}}$ & expected running time of vehicle i between stop k-1 and stop k (min) \\
\hline$\rho_{\mathrm{k}}$ & proportion of people who alight when vehicles arrive at stop k (\%) \\
\hline$T$ & length of time period (min) \\
\hline$L_{\mathrm{i}, \mathrm{k}}$ & total number of people on board when vehicle i leaves stop $\mathrm{k}$ \\
\hline$H_{\mathrm{ik}}$ & headway between vehicle $\mathrm{i}$ and the previous vehicle $(\mathrm{i}-1)$ at stop $\mathrm{k}(\mathrm{min})$ \\
\hline$H_{0}$ & origin stop headway before optimization of the route to be optimized (min) \\
\hline$B_{\mathrm{ik}}$ & the number of passengers boarding when vehicle $\mathrm{i}$ arrives at stop $\mathrm{k}$ \\
\hline$A_{\mathrm{ik}}$ & the number of passengers alighting when vehicle $\mathrm{i}$ arrives at stop $\mathrm{k}$ \\
\hline$U \mathrm{~B}_{\mathrm{ik}}$ & the number of passengers who fail to board when vehicle i leaves stop $k$ \\
\hline$R_{\mathrm{ik}}$ & running time of vehicle i starting from stop $(\mathrm{k}-1)$ to stop at stop $\mathrm{k}(\mathrm{min})$ \\
\hline$D_{\mathrm{ik}}$ & time for vehicle $\mathrm{i}$ arriving at stop $\mathrm{k}$ to allow passengers to board and alight(min) \\
\hline$r_{\mathrm{ik}}$ & proportion of passengers leaving stop $\mathrm{k}$ who had failed to board vehicle $\mathrm{i}-1$ before vehicle $\mathrm{i}$ arrived at stop $\mathrm{k}(\%)$ \\
\hline$W B_{\mathrm{ik}}$ & the total number of passengers waiting for vehicle $\mathrm{i}$ at stop $\mathrm{k}$ \\
\hline$R C_{\mathrm{ik}}$ & remaining passenger capacity when vehicle $\mathrm{i}$ arrives at stop $\mathrm{k}$ \\
\hline$L P_{\mathrm{ik}}$ & the number of passengers who leave stop $\mathrm{k}$ before vehicle $\mathrm{i}$ arrives. \\
\hline
\end{tabular}

\subsection{Description of the Problem}

This paper mainly addresses the problem of bus headway allocation in the operation mode when all stops are served but under uncertain conditions. Without loss of generality, this paper assumes that there are $K$ stops on a bus line, and several vehicles need to operate $n$ single trips from the origin stop $(\mathrm{k}=1)$ to the last stop $(\mathrm{k}=\mathrm{K})$ within a given time period. The problem to be solved in this paper is to find the optimal headway of the line under passenger demand elasticity, the randomness of the bus travel time between bus stops, and the abandoned passengers flow conditions. The model below is mainly based on study [15] and refers to some results of the literature [22-24]. The illustrative figures are shown as Figures 1 and 2 below: 


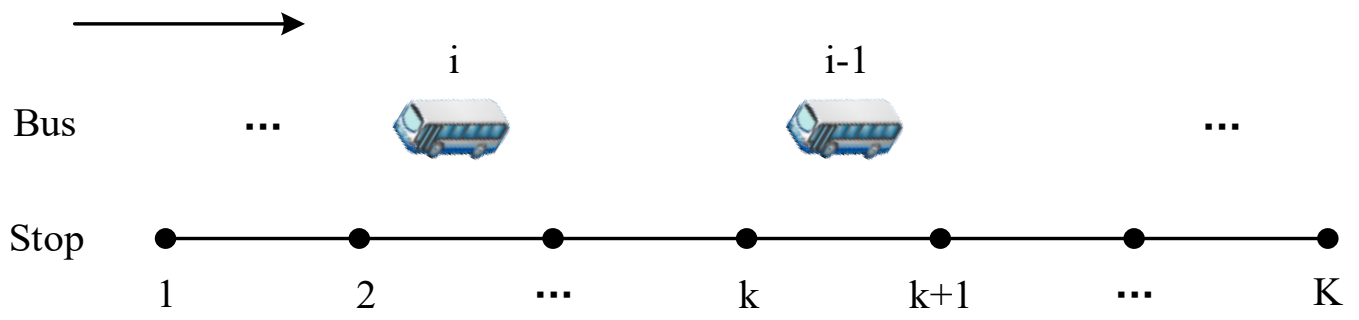

Figure 1. All-stop-serviced bus operation model.

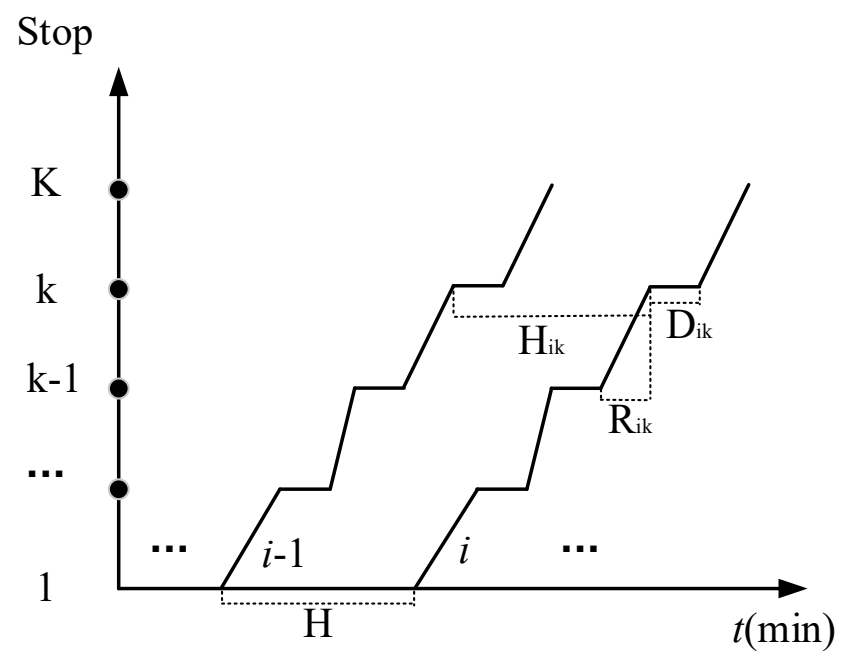

Figure 2. Bus operation diagram and some variables' graphic representation.

\subsubsection{Passenger Demand Elasticity}

The passenger demand at stop $\mathrm{k}$ is defined as the number of passengers waiting to board at stop $\mathrm{k}$ in a single trip, so the passenger demand of stop $k$ is $Q_{k}=W B_{k}$. $W B_{k}$ consists of two parts. The first part is the number of passengers arriving at stop $\mathrm{k}$ during a headway, and the second part is the number of passengers who fail to board because the bus is overloaded and then choose to wait for the subsequent vehicle. The passenger demand elasticity at stop $\mathrm{k}$ in this paper refers to the elasticity of the arrival rate, which reflects the number of vehicles serving stop $\mathrm{k}$.

The passenger demand elasticity in this paper relates to the number of vehicles serving the stop. The passenger demand elasticity coefficient $\varepsilon$ is related to the historical data of the passenger flow and headway of the time period, bus route and bus stop. It is therefore not affected by the number of buses currently serving the stop, and remains unchanged. Elastic theory in research such as the work by Verbas [23] is used in the single bus service mode of this paper, meaning the elasticity of the passenger arrival rate at stop $\mathrm{k}$ with respect to the number of vehicles serving that stop. So, according to the literature [24], combined with the model in this paper, the passenger arrival at stop $\mathrm{k}$ is as follows:

$$
\lambda_{k}(n)=C_{k}(n)^{\varepsilon}
$$

The number of vehicles $\mathrm{n}$ in study period $\mathrm{T}$ can be expressed as $\frac{T}{H} ; C_{k}$ is a passenger arriving constant, which is determined by $H_{0}$ and $\lambda_{\mathrm{k} 0}$ before the optimization of the bus route. It is, therefore, not affected by the change of the current headway. Therefore:

$$
C_{k}=\frac{\lambda_{k 0}}{\left(\frac{T}{H_{0}}\right)^{\varepsilon}}
$$

To organize the above formula, $\lambda_{k}$ can be expressed as: 


$$
\lambda_{k}(H)=\lambda_{k 0} \times\left(\frac{H_{0}}{H}\right)^{\varepsilon}
$$

Therefore, the number of passengers arriving at stop $\mathrm{k}$ during the $H_{\mathrm{ik}}$ period can be expressed as:

$$
\lambda_{\mathrm{k}} \times H_{\mathrm{ik}}=\lambda_{k 0} \times\left(\frac{H_{0}}{H}\right)^{\varepsilon} \times H_{\mathrm{ik}}
$$

\subsubsection{Abandoned Passenger Flow Calculation}

When the vehicle is overloaded, passengers who are unable to board at the stop will choose to either wait for the next bus or leave the stop to take another mode of transportation [21]. The loss of passengers is defined as the abandoned passenger flow in this paper.

Let $r_{\text {ik }}$ be the proportion of passengers who leave stop $\mathrm{k}$ after failing to board vehicle $\mathrm{i}-1$, and it consists of two parts. The first part is represented by $r_{k}^{0}$ which is related to the other transportation alternatives at the bus stop (other route options and other transportation modes). Assuming that the other transportation modes at stop $\mathrm{k}$ during the operation time are fixed, $r_{k}^{0}$ is only related to the location of the stop. The other part can be expressed as $r\left(H_{\mathrm{i}, \mathrm{k}}\right)^{\gamma}$ which is related to the waiting time of the passengers who fail to board (the headway of the vehicle $i$ and $i-1$ at stop $k$ ).

Therefore, after vehicle i arrives at stop $k$, the proportion of the abandoned passenger flow can be expressed as:

$$
r_{\mathrm{ik}}=r_{k}^{0}+r\left(H_{\mathrm{ik}}\right)^{\gamma}
$$

The abandoned passenger flow $L P_{\mathrm{ik}}$ can be expressed as:

$$
L P_{\mathrm{ik}}=U B_{\mathrm{i}-1, \mathrm{k}} \times r_{\mathrm{ik}}
$$

The number of passengers who fail to board and still choose to wait for the next bus at stop $\mathrm{k}$ can be expressed as:

$$
U B_{\mathrm{i}-1, \mathrm{k}}-L P_{\mathrm{ik}}=U B_{\mathrm{i}-1, \mathrm{k}} \times\left(1-r_{\mathrm{ik}}\right)
$$

The passenger demand for vehicle $i$ at stop $k$ is equal to the number of passengers waiting to board vehicle $\mathrm{i}$ at stop $\mathrm{k}$, which means $W B_{\mathrm{ik}}=Q_{\mathrm{ik}}$. So $W B_{\mathrm{ik}}$ can be expressed as follows:

$$
W B_{\mathrm{ik}}=\lambda_{\mathrm{k}} \times H_{\mathrm{ik}}+U B_{\mathrm{i}-1, \mathrm{k}} \times\left(1-r_{\mathrm{ik}}\right)
$$

The calculation of the above variables needs to be performed for the subsequent analysis process, as follows:

When vehicle $\mathrm{i}$ arrives at stop $\mathrm{k}$, the vehicle's remaining capacity $R C_{\mathrm{ik}}$ can be expressed as:

$$
R C_{\mathrm{ik}}=\mathrm{C}-\left(1-\rho_{\mathrm{k}}\right) \times L_{\mathrm{i}, \mathrm{k}-1}
$$

It is assumed that the number of passengers alighting is subject to the binomial distribution, and that the proportion of passengers alighting relative to the total number of passengers on the bus is $\rho_{\mathrm{k}}$. Therefore, $A_{\mathrm{ik}}$ can be expressed as:

$$
A_{\mathrm{ik}}=\rho_{\mathrm{k}} \times L_{\mathrm{i}, \mathrm{k}-1}
$$

The number of passengers who could board vehicle $\mathrm{i}$ is influenced by $R C_{\mathrm{ik}}$ and $W B_{\mathrm{ik}}$, so:

$$
B_{\mathrm{ik}}=\min \left(R C_{\mathrm{ik}}, W B_{\mathrm{ik}}\right)
$$

Due to the limitation of the vehicle capacity, not all of the waiting passengers can board. The number of people who cannot board is related to $R C_{\mathrm{ik}}$ and $W B_{\mathrm{ik}}$ when vehicle $\mathrm{i}$ arrives at stop $\mathrm{k}$.

$$
\mathrm{UB}_{\mathrm{ik}}=\max \left(0, W B_{\mathrm{ik}}-R C_{\mathrm{ik}}\right)
$$


When vehicle i leaves stop $\mathrm{k}$ after service ends, the number of passengers in the vehicle is as follows:

$$
L_{\mathrm{ik}}=L_{\mathrm{i}, \mathrm{k}-1}-A_{\mathrm{ik}}+B_{\mathrm{ik}}
$$

\subsubsection{Random Travel Time Between Bus Stops}

The expected traveling time between stops is affected by the distance and road traffic conditions etc. Considering the impact of these factors, the actual traveling time between bus stops fluctuates around the expected time. According to Mishalani et al. [29] and Hadas and Shnaiderman [28], the time of vehicle $\mathrm{i}$ traveling from stop $\mathrm{k}-1$ to stop $\mathrm{k}$ is as follows:

$$
R_{\mathrm{ik}}=\mu_{\mathrm{ik}}+\xi
$$

where $\mu_{\mathrm{ik}}$ denotes the expected traveling time of vehicle i running from stop $\mathrm{k}-1$ to stop $\mathrm{k}$, and $\xi$ is a normally distributed disturbance term with an expected value of zero.

Since the running time of the bus between the stops is random, the headway of the adjacent vehicles will also change with the randomness of the travel time. Thus, the dynamic headway $H_{\mathrm{ik}}$ can be expressed as:

$$
H_{\mathrm{ik}}=H_{\mathrm{i}, \mathrm{k}-1}+R_{\mathrm{ik}}-R_{\mathrm{i}-1, \mathrm{k}}+D_{\mathrm{i}, \mathrm{k}-1}-D_{\mathrm{i}-1, \mathrm{k}-1}
$$

Since $H_{\mathrm{ik}}$ refers to the headway between vehicle $\mathrm{i}$ and vehicle $\mathrm{i}-1$ at stop $\mathrm{k}$, the influence of the passengers' arrival during the passenger's boarding/alighting is ignored. The dynamic headway is mainly due to the vehicle travel time $R$. The randomness of the headway can be obtained according to a certain probability function.

It is assumed that passengers board/alight at the same time, so the time that vehicle i spends at stop $\mathrm{k}$ depends on the maximum of the passengers' boarding time and alighting time at the stop.

$$
D_{\mathrm{ik}}=\max \left(\alpha \times A_{\mathrm{ik}}, \beta \times B_{\mathrm{ik}}\right)
$$

\subsection{Mathematical Model}

\subsubsection{The Assumptions}

Without any loss of generality and rigor, the conditions of the model are defined according to the actual operation situation.

(1) Passengers arriving at the bus stop obey a certain probability distribution of first-come first-served.

(2) The number of passengers alighting is proportional to the total number of passengers on the bus when the bus arrives at the stop.

(3) Passengers board and alight at the same time and the bus service time at the stop depends on the maximum time of passengers boarding/alighting. The time per passenger to board/alight is constant.

(4) The capacity of the vehicles on the same bus route is the same and is fixed;

(5) The traveling time of vehicles serving the same route is the same probability distribution and independent.

(6) The departure stop in the bus route has a sufficient number of buses to ensure daily operations.

\subsubsection{Model Description}

This paper establishes an optimization model for the bus headway with two objective functions $Z_{1}$ and $Z_{2}$. In order to increase the attractiveness of bus traveling and focus more on sustainability of 
bus system, the maximum number of passengers waiting for the buses at each stop is used as $Z_{1}$, so it can be expressed as the following:

$$
\operatorname{Max} Z_{1}=\left(\sum_{i=1}^{N} \sum_{k=0}^{K-1} W B_{i k}\right) /(N \times(K-1))
$$

The number of passengers who fail to board should be the minimum to express the passengers' interest. This part of objective function $Z_{2}$ can be expressed as:

$$
\operatorname{Min} Z_{2}=\sum_{i=1}^{N} \sum_{k=0}^{K-1} U B_{i k}
$$

Objective function normalization:

$$
\operatorname{Max} Z=\omega_{1} Z_{1}-\omega_{2} Z_{2}
$$

s.t.

$$
\begin{aligned}
& H_{\text {min }} \leq H \leq H_{\text {max }} \\
& 0 \leq r_{\mathrm{ik}} \leq 1 \\
& B_{\mathrm{ik}}= \begin{cases}W B_{i k} & W B_{i k}<R C_{i k} \\
R C_{i k} & R C_{i k}<W B_{i k}\end{cases} \\
& U B_{\mathrm{ik}}= \begin{cases}0 & W B_{i k}<R C_{i k} \\
W B_{i k}-R C_{i k} & R C_{i k}<W B_{i k}\end{cases}
\end{aligned}
$$

The first constraint condition (20) represents the upper and lower limits of the bus headway of the first stop, wherein the minimum interval is determined by the bus enterprise according to its own resources, and the maximum interval is prescribed by the government department to ensure the minimum service level of the bus. The second constraint (21) represents the range of the proportion of abandoned passenger flow; the third constraint (22) represents the number of people who can board when vehicle $i$ arrives at stop $k$. The fourth constraint (23) indicates the number of passengers who fail to board.

\section{The Solving Algorithm}

From the above formula derivation process, the model is transitive and iterative by giving the initial conditions. It can be solved by using a combined recursive and enumeration method. At the same time, due to the need to generate random numbers to express the bus travel time between stops, this paper uses the combined enumeration and recursive algorithm under Monte Carlo random simulation conditions which is shown as Algorithm 1 below. The result will fluctuate because of the random number, so the expected value of multiple calculation results is used as the final result.

After the end of the loop, find the maximum value maxZ and the corresponding departure interval $H$. 


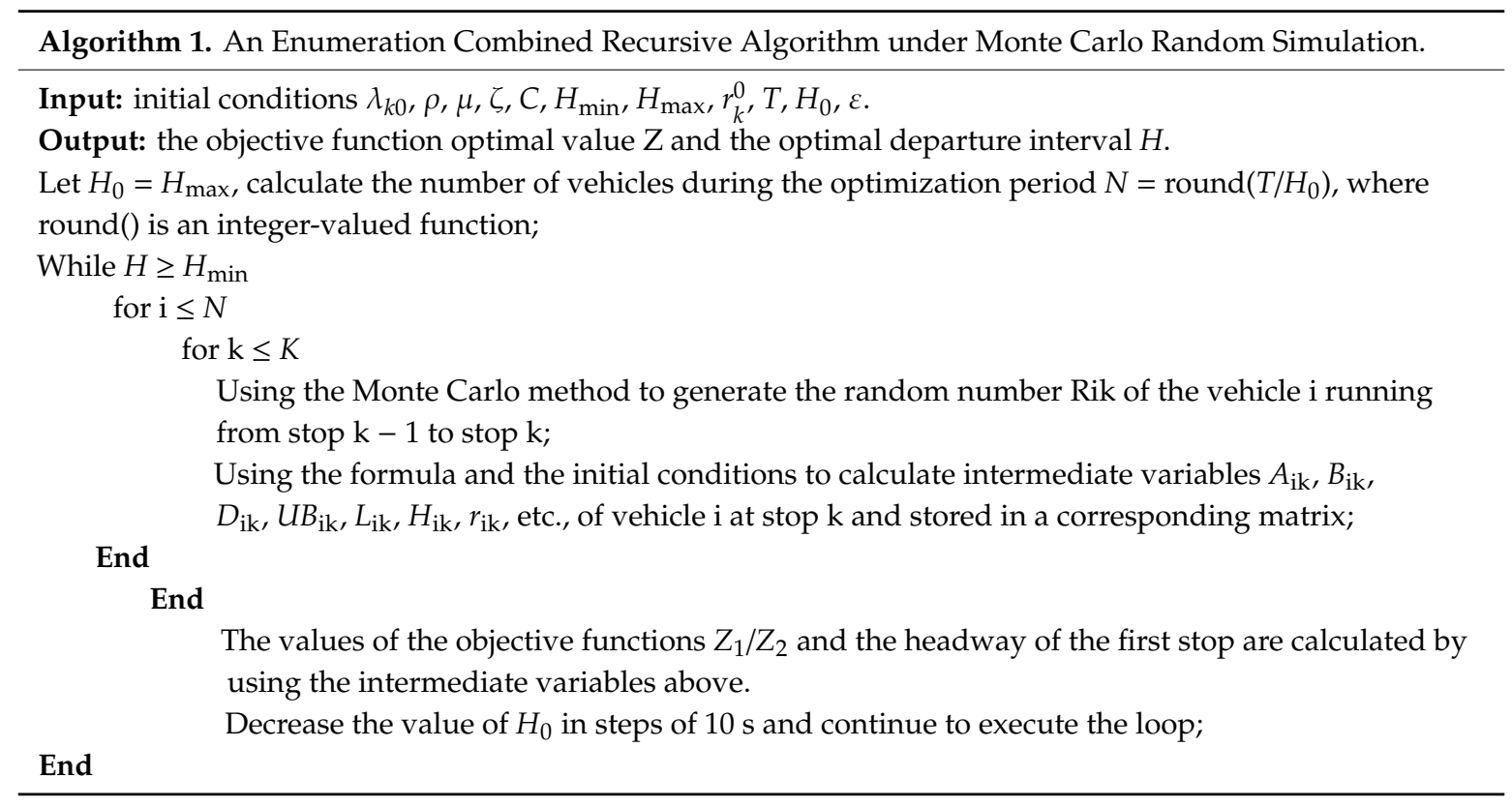

\section{Case Analysis}

\subsection{Experimental Line Description}

There are 21 bus stops in a bus route, $\mathrm{k}=1,2,3 \ldots 21$. The optimization period of this paper is from 6:10 a.m. to 7:10 a.m. which means $T=60$. It is assumed that it takes $3.0 \mathrm{~s}$ per passenger to board and $1.8 \mathrm{~s}$ to alight, which is $\alpha=0.05, \beta=0.03$ [15]. The other related parameters and passenger flow data are shown in Tables 2 and 3.

Table 2. Related parameter values.

\begin{tabular}{cccccccc}
\hline$\alpha(\min )$ & $\boldsymbol{\beta}(\min )$ & $\boldsymbol{r}$ & $\gamma$ & $\boldsymbol{C}$ (seats) & $\boldsymbol{H}_{\mathbf{0}}(\min )$ & $\boldsymbol{H}_{\max }(\min )$ & $\mathbf{H}_{\min }(\min )$ \\
\hline 0.05 & 0.03 & 0.1 & 0.1 & 80 & 10 & 20 & 2 \\
\hline
\end{tabular}

Table 3. Initial line data during the time period.

\begin{tabular}{ccccccc}
\hline Stop Num. & $\lambda_{\mathbf{k} \mathbf{0}}(\mathbf{p} / \mathbf{m i n})$ & $\rho_{\mathbf{k}}(\mathbf{\%})$ & $\mu(\mathbf{m i n})$ & $\sigma \mathbf{2}$ & $\boldsymbol{r}_{\boldsymbol{k}}^{\mathbf{0}} \mathbf{( \% )}$ & $\varepsilon$ \\
\hline 1 & 0.75 & 0 & - & - & 0 & 0.5 \\
2 & 1.0 & 0 & 1.4 & 0.3 & 0 & 0.5 \\
3 & 1.5 & 0.1 & 2.0 & 1.0 & 0 & 0.5 \\
4 & 1.0 & 0.25 & 1.7 & 0.4 & 0 & 0.3 \\
5 & 3.0 & 0.25 & 1.6 & 0.4 & 0 & 0.3 \\
6 & 2.5 & 0.5 & 2.0 & 0.8 & 0 & 0.3 \\
7 & 2.0 & 0.25 & 1.25 & 0.2 & 0 & 0.4 \\
8 & 1.5 & 0.25 & 1.8 & 0.6 & 0 & 0.2 \\
9 & 0.75 & 0.2 & 1.4 & 0.2 & 0 & 0.5 \\
10 & 1.0 & 0.1 & 2.5 & 1.0 & 0.1 & 0.5 \\
11 & 0.75 & 0.25 & 1.25 & 0.2 & 0 & 0.3 \\
12 & 1.0 & 0.2 & 1.6 & 0.4 & 0 & 0.2 \\
13 & 2.0 & 0.3 & 1.3 & 0.4 & 0 & 0.3 \\
14 & 3.0 & 0.25 & 1.3 & 0.2 & 0 & 0.4 \\
15 & 1.75 & 0.5 & 2.3 & 0.8 & 0 & 0.4 \\
16 & 1.5 & 0.3 & 2.6 & 1.0 & 0 & 0.2 \\
17 & 0.75 & 0.4 & 1.7 & 0.4 & 0 & 0.5 \\
18 & 0.5 & 0.5 & 1.25 & 0.2 & 0 & 0.5 \\
19 & 0.5 & 0.2 & 1.7 & 0.2 & 0.2 & 0.3 \\
20 & 0.0 & 0.75 & 2.8 & 1.0 & 0.2 & 0.4 \\
21 & 0.0 & 1.0 & 1.5 & 0.4 & 0 & 0 \\
\hline
\end{tabular}


The distribution law of passenger flow for this route is shown in Figure 3. The passenger flow has two peaks in the spatial distribution.

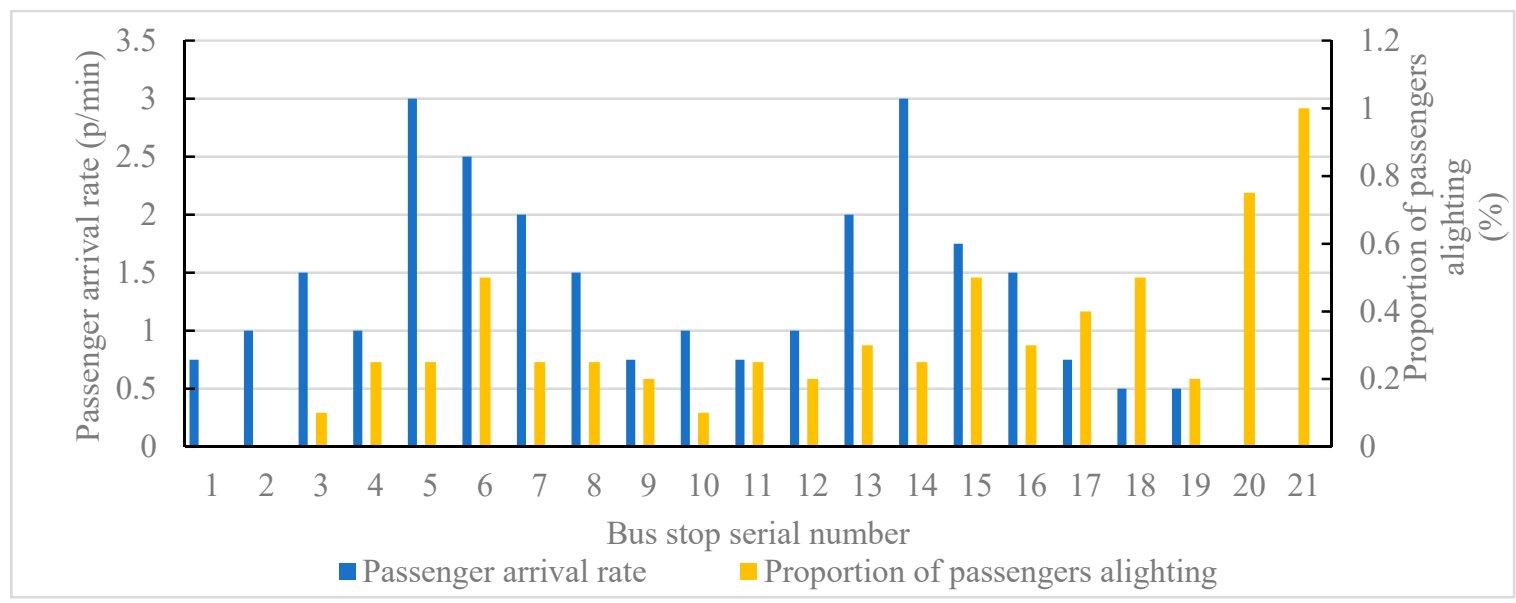

Figure 3. Passenger flow spatial distribution.

\subsection{Determine the Weight of the Objective Function}

The model is solved by MATLAB, and the iteration step length is $10 \mathrm{~s}$ [15]. The objective function consists of two parts. The total number of transported passengers is regarded as a key factor in determining the weights of the objective functions in this paper. The results under different weights are shown in Table 4. As we can see, the total number of transported passengers under the weight of $0.1 / 0.9$ is larger than other sets, which means more passengers choose to travel by bus. Thus, the weight of $Z_{1} / Z_{2}$ in this case is set to $0.1 / 0.9$.

Table 4. The results under different weights of $Z_{1} / Z_{2}$.

\begin{tabular}{ccccccc}
\hline Weight of $\mathbf{Z 1 / Z 2}$ & $\mathbf{0 / 1}$ & $\mathbf{0 . 1 / 0 . 9}$ & $\mathbf{0 . 2 / 0 . 8}$ & $\mathbf{0 . 3 / 0 . 7}$ & $\mathbf{0 . 4 / 0 . 6}$ & $\mathbf{0 . 5 / 0 . 5}$ \\
\hline Optimal departure interval (Min) & 9.3 & 9.2 & 9.3 & 9.3 & 9.5 & 9.6 \\
Total transported passengers (p) & 1627 & 1636 & 1631 & 1624 & 1616 & 1605 \\
\hline Weight of Z1/Z2 & $\mathbf{0 . 6 / 0 . 4}$ & $\mathbf{0 . 7 / 0 . 3}$ & $\mathbf{0 . 8 / 0 . 2}$ & $\mathbf{0 . 9 / 0 . 1}$ & $\mathbf{1 / 0}$ & \\
\hline Optimal departure interval (Min) & 9.8 & 10.1 & 10.4 & 11.1 & 19.7 & \\
Total transported passengers (p) & 1595 & 1569 & 1556 & 1508 & 1099 & \\
\hline
\end{tabular}

\subsection{Determine the Number of Algorithm Repetitions}

The random number generated during the Monte Carlo simulation process will cause the optimal value of the output to fluctuate, resulting in random errors. The method for solving this random error is to get the expected value of multiple calculation results as the final result. In this paper, six sets of experiments are set up, and the algorithm is repeated once, 10 times, 50 times, 100 times, 200 times, and 300 times. Each of these experiments tests 10 times to get 10 departure intervals, and analyzes the trend of the solution under different numbers of repetitions. The trend is shown in Figure 4.

As the number of repetitions increases, the ten values of each repetition have a clear convergence trend, indicating that the results are more stable. When the algorithm is repeated 300 times, the intra-group variance of the 10 values is 0.0023 and any one of the results can be used as the final value. 


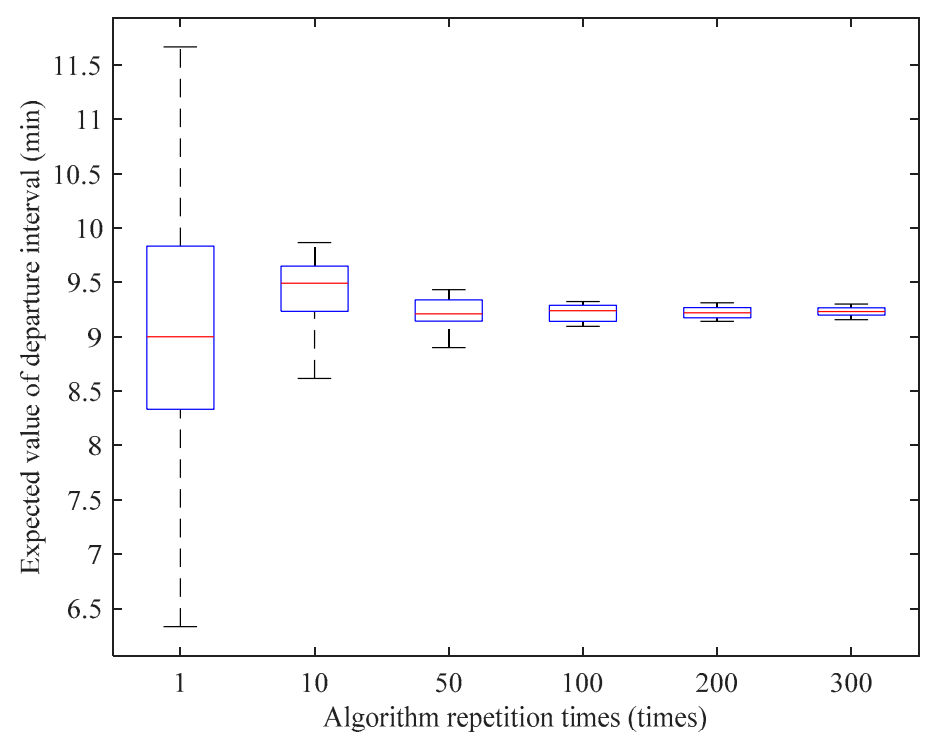

Figure 4. Departure interval box plot under different algorithm repetition times.

\subsection{Comparative Experiment}

So as to determine the influence of the three factors on the model objective function and the departure interval, this paper combines the three factors, and eight sets of comparative tests were set up. The results are shown in Table 5.

Table 5. Comparison of experiments and results.

\begin{tabular}{|c|c|c|c|c|}
\hline Scenarios & Experiment Conditions & $\begin{array}{l}\text { Optimal Departure } \\
\text { Interval (Min) }\end{array}$ & $\begin{array}{l}\text { Total Transported } \\
\text { Passengers (p) }\end{array}$ & $\begin{array}{l}\text { Average Waiting } \\
\text { Time (Min) }\end{array}$ \\
\hline 1 & $\begin{array}{l}\text { Passenger flow is inelastic, No } \\
\text { abandoned passenger flow, Fixed } \\
\text { vehicle running time }\end{array}$ & 11.0 & 1471 & 4.4 \\
\hline 2 & $\begin{array}{l}\text { Passenger flow is inelastic, No } \\
\text { abandoned passenger flow, Vehicle } \\
\text { running time is random }\end{array}$ & 9.7 & 1602 & 4.1 \\
\hline 3 & $\begin{array}{l}\text { Passenger flow is inelastic, } \\
\text { Considering abandoned passenger } \\
\text { flow, Fixed vehicle running time }\end{array}$ & 11.0 & 1471 & 4.4 \\
\hline 4 & $\begin{array}{l}\text { Passenger flow is inelastic, } \\
\text { Considering abandoned passenger } \\
\text { flow, Vehicle running time } \\
\text { is random }\end{array}$ & 10.0 & 1595 & 4.2 \\
\hline 5 & $\begin{array}{l}\text { Passenger flow is elastic, No } \\
\text { abandoned passenger flow, Fixed } \\
\text { vehicle running time }\end{array}$ & 11.7 & 1477 & 4.7 \\
\hline 6 & $\begin{array}{l}\text { Passenger flow is elastic, No } \\
\text { abandoned passenger flow, Vehicle } \\
\text { running time is random }\end{array}$ & 9.4 & 1626 & 4.0 \\
\hline 7 & $\begin{array}{l}\text { Passenger flow is elastic, } \\
\text { Considering abandoned passenger } \\
\text { flow, Fixed vehicle running time }\end{array}$ & 11.7 & 1477 & 4.7 \\
\hline 8 & $\begin{array}{l}\text { Passenger flow is elastic, } \\
\text { Considering abandoned passenger } \\
\text { flow, Vehicle running time } \\
\text { is random }\end{array}$ & 9.2 & 1636 & 3.9 \\
\hline
\end{tabular}




\subsection{Analysis of Results}

The results from the eight sets of experiments are shown in Table 5. After analysis, the following conclusions can be obtained.

It can be seen from Table 5 that the total number of the transported passengers in Scenario 8 is larger than other experiments. It also shows that the optimal departure interval in Scenario 8 is the shortest one and the average waiting time per passenger is less than others, which coincides with Welding's findings [30]. The above results indicate that the proposed model improves the attractiveness of the bus system and serves more passengers by considering these three uncertain factors comprehensively.

\section{Conclusions}

This model takes into account the randomness of the running time between bus stops, passenger flow elasticity at the stop, and the abandoned passenger flow. The objective functions are maximizing the number of passengers waiting for the buses at each stop and minimizing the number of passengers who fail to board. It is more in line with the reality of bus operations.

The model proposed in this paper promises to transport more passengers by considering those three uncertainties. As for the whole transit system, the model we proposed can attract more passengers traveling by bus and positively promote the sustainable development of the public transport system.

Passenger flow elasticity is the sensitivity of the passenger arrival rate to the number of public transportation vehicles. The departure interval affects passengers' abandonment behavior and that conforms the decision-making behavior of the passengers. Therefore, this model is closer to the reality of bus operation and increases the robustness of the model by considering these three uncertain factors comprehensively. Thus, it provides another view for bus enterprises to optimize and refine the headway as well as provides a reference for the government to promote public transport development.

But there are also some limitations in this model, which can be solved through further study. The passenger demand elasticity in this study is an elasticity with respect to the supply of service, and thus ignores the influences of other factors such as ticket price and land use around bus stops, etc. Additionally, there are also no economic parameters considered directly in the modeling, such as passenger's cost or bus operation cost, so some economic factors can be added in future modeling to make the model more intuitive in comparison with other studies.

Author Contributions: W.C. and X.L. conceived and designed the study; X.L. established the models and conducted the data experiments; X.L., D.C. and X.P. were responsible for data analysis and editing; X.L. wrote the paper and W.C. helped to modify the paper.

Funding: This research was supported by the Natural Science Foundation of Hunan Province, 2018JJ2537 Science Progress and Innovation Program of Hunan DOT, 201723. This research was also supported by National Natural Science Foundation of China, 61203162.

Acknowledgments: The authors would like to acknowledge the anonymous reviewers for their valuable comments.

Conflicts of Interest: The authors declare no conflict of interest. And the funders had no role in the design of the study; in the collection, analyses, or interpretation of data; in the writing of the manuscript, or in the decision to publish the results.

\section{References}

1. Jalalian, M.; Gholami, S.; Ramezanian, R. Analyzing the trade-off between CO2 emissions and passenger service level in the airline industry: Mathematical modeling and constructive heuristic. J. Clean. Prod. 2019, 206, 251-266. [CrossRef]

2. Dulebenets, M.A. A comprehensive multi-objective optimization model for the vessel scheduling problem in liner shipping. Int. J. Prod. Econ. 2018, 196, 293-318. [CrossRef]

3. Wagenaar, J.; Kroon, L.; Fragkos, I. Rolling stock rescheduling in passenger railway transportation using dead-heading trips and adjusted passenger demand. Transp. Res. Part B Methodol. 2017, 101, $140-161$. [CrossRef] 
4. Liu, L.; Chen, R.C. A novel passenger flow prediction model using deep learning methods. Transp. Res. Part C Emerg. Technol. 2017, 84, 74-91. [CrossRef]

5. Liu, Z.; Yan, Y.; Qu, X.; Zhang, Y. Bus stop-skipping scheme with random travel time. Transp. Res. Part C Emerg. Technol. 2013, 35, 46-56. [CrossRef]

6. Newell, G.F. Dispatching policies for a transportation route. Transp. Sci. 1971, 5, 91-105. [CrossRef]

7. Han, A.F.; Wilson, N.H.M. The allocation of buses in heavily utilized network with overlapping routes. Transp. Res. Part B Methodol. 1982, 16, 221-232. [CrossRef]

8. Lam, W.H.K.; Gao, Z.Y.; Chan, K.S.; Yang, H. A Stochastic User Equilibrium Assignment Model for Congested Transit Networks. Transp. Res. Part B 1999, 33, 351-368. [CrossRef]

9. Valouxis, C.; Housos, E. Combined bus and driver scheduling. Comput. Oper. Res. 2002, 29, $243-259$. [CrossRef]

10. Lu, F.; Chen, X.u.; Chen, S. Frequency optimization of bus rapid transit based on cost analysis. J. Southeast Univ. (Natl. Sci. Ed.) 2009, 39, 850-853.

11. Ceder, A.; Golany, B.; Tal, O. Creating bus timetables with maximal synchronization. Transp. Res. Part A Policy Pract. 2001, 35, 913-928. [CrossRef]

12. Niu, X.; Chen, W.; Wang, W. Optimal model of urban bus frequency determination. J. Traffic Transp. Eng. 2003, 3, 87-94.

13. Furth, P.G.; Wilson, N.H.M. Setting frequencies on bus routes: Theory and practice. Transp. Res. Board 1981, $818,1-7$.

14. Wang, C.; Xu, M. An Optimal Bus Headway Model Considering Traffic Congestion. J. Transp. Syst. Eng. Inf. Technol. 2011, 4, 166-172.

15. Chen, W.; Chen, Z. An optimal model for fixed-route bus service frequency determination considering stochastic conditions. J. Wuhan Univ. Technol. (Transp. Sci. Eng.) 2011, 35, 1108-1111.

16. Li, Y.; Xu, W.; He, S. Expected value model for optimizing the multiple bus headways. Appl. Math. Comput. 2013, 219, 5849-5861. [CrossRef]

17. Luigi, D.O.; Angel, I.; Francisco, R. Optimizing bus-size and headway in transit networks. Transportation 2012, 39, 449-464.

18. Sharma, R.R.; Rai, R.C.; Mishra, A. Optimal bus services on express basis in the case of balking and reneging. Eur. J. Oper. Res. 1993, 66, 113-123. [CrossRef]

19. Ceder, A. Public Transit Planning and Operation: Theory, Modeling and Practice; Butterworth-Heinemann: Oxford, UK, 2007.

20. Delle Site, P.; Filippi, F. Service optimization for bus corridors with short-turn strategies and variable vehicle size. Transp. Res. Part A Policy Pract. 1998, 32, 19-28. [CrossRef]

21. Yulin, L.; Bunker, J.; Ferreira, L. Transit users' route-choice modelling in transit assignment: A review. Transp. Rev. 2010, 30, 753-769.

22. Herbon, A.; Hadas, Y. Determining optimal frequency and vehicle capacity for public transit routes: A generalized newsvendor model. Transp. Res. Part B 2015, 71, 85-99. [CrossRef]

23. Verbas, I.O.; Mahmassani, H.S. Exploring Trade-Offs in Frequency Allocation in a Transit Network Using Bus Route Patterns: Methodology and Application to Large-Scale Urban Systems. Transp. Res. Part B Methodol. 2015, 81, 577-595. [CrossRef]

24. Tian, S. Study on Multi-mode Bus Frequency Allocation Based on Stop Demand Elasticity. Master's Thesis, Chang'an University, Xi'an, China, 2017.

25. Frei, C.; Mahmassani, H.S. Riding More Frequently: Estimating Disaggregate Ridership Elasticity for a Large Urban Bus Transit Network. Transp. Res. Rec. J. Transp. Res. Board 2013, 2350, 65-71. [CrossRef]

26. Sivakumaran, K.; Li, Y.; Cassidy, M.J.; Samer, M. Cost-saving properties of schedule coordination in a simple trunk-and-feeder transit system. Transp. Res. Part A Policy Pract. 2012, 46, 131-139. [CrossRef]

27. Verbas, I.O.; Frei, C.; Mahmassani, H.S.; Raymond, C. Stretching Resources: Sensitivity of Optimal Bus Frequency Allocation to Stop-Level Demand Elasticities. Public Transp. 2015, 7, 1-20. [CrossRef]

28. Hadas, Y.; Shnaiderman, M. Public-transit frequency setting using minimum-cost approach with stochastic demand and travel time. Transp. Res. Part B 2012, 46, 1068-1084. [CrossRef] 
29. Mishalani, R.G.; McCord, M.R.; Forman, S. Schedule-Based and Autoregressive Bus Running Time Modeling in the Presence of Driver-Bus Heterogeneity. In Computer-Aided Systems in Public Transport; Springer: Berlin, Germany, 2008; pp. 301-317.

30. Welding, P.I. The instability of a close-interval service. Op. Res. Quart. 1957, 8, 133-148. [CrossRef]

(C) 2019 by the authors. Licensee MDPI, Basel, Switzerland. This article is an open access article distributed under the terms and conditions of the Creative Commons Attribution (CC BY) license (http://creativecommons.org/licenses/by/4.0/). 